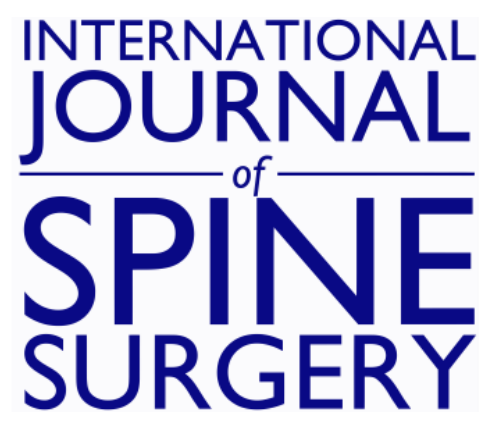

\title{
The Functional Anaesthetic Discogram: Description of a Novel Diagnostic Technique and Report of 3 Cases
}

Todd Alamin, Farbod Malek, Eugene Carragee and Mi-Jung Kim

Int J Spine Surg 2008, 2 (2) 107-113

doi: https://doi.org/10.1016/SASJ-2007-0123-NT

http://ijssurgery.com/content/2/2/107

This information is current as of April 26, 2023.

Email Alerts Receive free email-alerts when new articles cite this article. Sign up at:

http://ijssurgery.com/alerts

The International Journal of Spine Surgery

2397 Waterbury Circle, Suite 1,

Aurora, IL 60504, Phone: +1-630-375-1432

(C) 2008 ISASS. All Righfso Refservededom http://ijssurgery.com/ by guest on April 26, 2023 


\title{
The Functional Anaesthetic Discogram: Description of a Novel Diagnostic Technique and Report of 3 Cases
}

\author{
Todd Alamin, MD, ${ }^{a}$ Farbod Malek, $M D,{ }^{a}$ Eugene Carragee, $M D,{ }^{a}$ \\ and Mi-Jung Kim, MD, PhD ${ }^{b}$
}

\begin{abstract}
Background

The diagnostic evaluation of patients with presumed discogenic low back pain is controversial; recent studies have brought the specificity of the traditional technique, provocative lumbar discography, into question. One of the explanations for the relative lack of predictability in treatment outcomes for patients with discogenic low back pain may be a corresponding lack of certainty in the diagnosis.
\end{abstract}

\section{Purpose}

A new diagnostic technique is described for the evaluation of patients with presumptive discogenic low back pain; the cases of 3 patients in whom the technique was used are presented.

\section{Study Design/Setting}

Case report; university practice.

\section{Methods}

A technique is described in which an anaesthetic catheter is placed into putative symptomatic lumbar discs, the patient elicits his or her typical pain via a position or activity, and anaesthetic or placebo is delivered to the disc. The effect of the injected substance on the patient's pain is then noted.

Results

In one patient, the new test was confirmatory of the results of the provocative discogram; in two patients, the test results were divergent.

\section{Conclusions}

These case studies and technical description are presented as a first step in examining this method of preoperative assessment. Further study of the technique will allow us to make more definitive recommendations with regards to its validity and utility.

\section{Level of Evidence}

Level 4 - Case Series

Key Words: Discography, functional anaesthetic discogram, discogenic pain, diagnosis. SAS Journal. Spring 2008;2:107-113. DOI: SASJ-2007-0123-NT

${ }^{a}$ Orthopaedics Surgery, Stanford University, Stanford, California; ${ }^{b}$ Physiatry Department, Hanyang University, Seoul, South Korea Address correspondence to Todd Alamin, MD, Stanford University - Orthopaedic Surgery, 300 Pasteur Drive, Room R-171, Stanford, CA 92405

Todd Alamin, MD, is a consultant to Kyphon Inc.; Todd Alamin, MD, receives royalties from Kyphon in relation to the FAD catheter. Institutional Review Board approval was obtained from Stanford University Medical Center.

\section{INTRODUCTION}

Recent US Food and Drug Administration approval of the first lumbar disc replacement has focused clinical and media attention on discogenic low back pain, the severity and import of the clinical syndrome, and the difficulties entailed in its surgical treatment. Much of this attention has been directed to the different but commonly applied treatment modalities (surgical versus physical therapy, fusion versus disc replacement), and their respective likelihood of achieving clinical success. Yet clearly this likelihood is significantly impacted by the certainty of the pretreatment clinical diagnosis. It is commonly accepted that there is, unfortunately, no "gold standard" test to confirm that a lumbar disc or discs is the primary cause of a given patient's low back pain. This fact complicates the ability to assess the effectiveness of any surgical strategy to treat the condition. Careful analysis of the results of fusion for discogenic low back pain suggests a bimodal distribution of outcomes, which can be interpreted as an outcome effect due to error in diagnosis. ${ }^{1-3}$ The likely prevalence of errors 
in diagnosis limits the possible effectiveness of any specific treatment modality: any treatment method (even one that is $100 \%$ effective) will fail clinically at a rate that is at least the false-positive rate of the method of securing the diagnosis, minus the placebo and nonspecific response rates.

In considering surgical options, it is important to obtain a correct and specific diagnosis of disabling low back pain when only common degenerative changes are found on imaging studies. Currently available diagnostic techniques have a number of limitations. Provocative discography is a commonly used and controversial diagnostic technique that has been used since the $1940 \mathrm{~s} .{ }^{4}$ Provocative discography involves the insertion of a needle into an intervertebral disc and the injection of contrast agent into the nucleus pulposus under pressure. The clinician then assesses the radiographic appearance of the disc, and more significantly, the patient's pain response to injection, which may be severe and similar to or exactly like their usual symptoms. Recent literature suggests that the onset of pain at a lower injection pressure is more suggestive of a "true positive" test result. ${ }^{5,6}$

The standard interpretation of the test is that if a discogram is positive according to several commonly used criteria, then the tested disc is the primary source of the patient's pain. ${ }^{7,8}$ However, there is no universally accepted definition of the criteria for a positive discogram, and no gold standard to compare competing diagnostic strategies. As a result, the interpretation of discography has been a longstanding controversy. Not only does the test rely on subjective feedback, but results themselves have been shown to have a high rate of false positives and false negatives, with up to 30 $40 \%$ of patients with no back pain having positive findings on discography. ${ }^{9,10}$ Similarly, some patients have reported feeling a replication of their usual pain during discography, even though it is later found that another, non-discogenic cause was the actual origin of the pain. These observations suggest that the test is not highly specific. ${ }^{11}$

\section{The Functional Anaesthetic Discogram}

To address this problem with the diagnosis of discogenic low back pain, the primary author (T.F.A.) have designed a new test, the Functional Anaesthetic Discogram (FAD). This test involves first a standard provocative discogram using a 2-needle technique (outer needle 18-gauge (18g), inner needle $22 \mathrm{~g}$ or $25 \mathrm{~g}$ ). Once candidate painful discs are noted on provocative discography, the next step involves the placement of a catheter into the relevant lumbar discs that were either painful on injection or radiographically highly suggestive of being a possible pain generator.

In the early experience with the technique, the outer $18 \mathrm{~g}$ needle was then inserted into the center of the involved disc, with care being taken to avoid irritation of the exiting nerve root at this level. An epidural catheter (20-gauge (20g)) was then modified via removal of the distal portion of the catheter including the side ports. The catheter was then carefully threaded into the involved disc, followed by removal of the outer $18 \mathrm{~g}$ needle while attempting to maintain the catheter position inside the nucleus. A Tuohy-Borst adaptor was then attached to the proximal end of the catheter and contrast introduced to ensure that the tip of the catheter was still intradiscal. The contrast was then flushed out of the catheter with injectable normal saline. Next the catheter was attached to the patient's skin in a sterile fashion (Figure 1), and the patient was allowed to recover from the procedure in the post anaesthesia care unit. A dedicated FAD catheter (Kyphon Inc., Sunnyvale, California) was recently approved by the FDA and is commercially available; it is inserted over a guidewire and has a balloon anchor at its tip, which prevents migration of the catheter out of the disc during functional testing.

\section{Figure 1.}

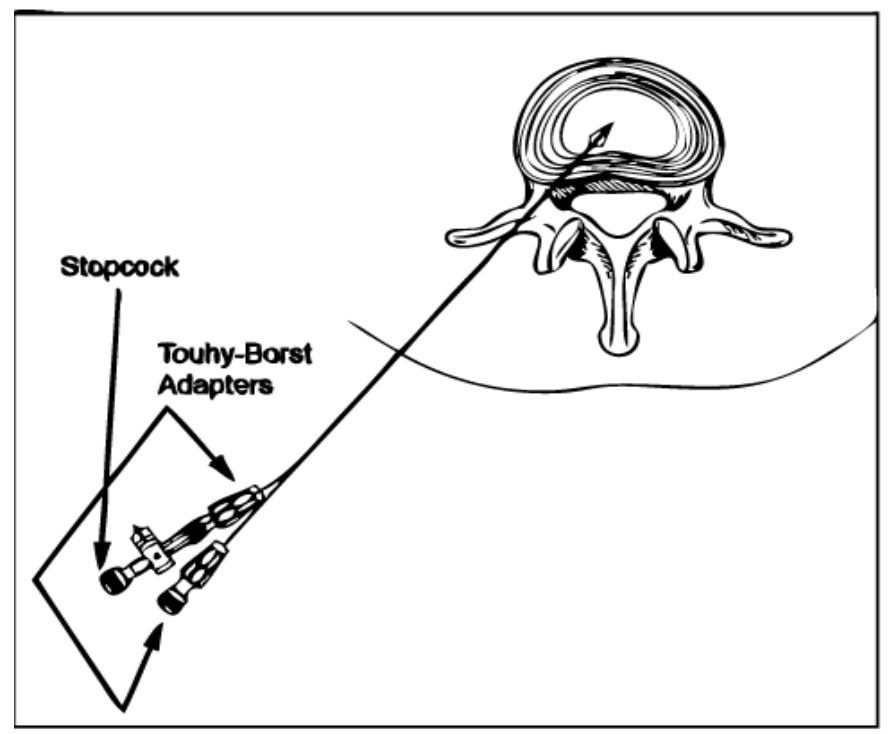

FAD catheter with balloon anchor deployed.

The patient is then allowed to recover from sedation and assume a position or begin an activity that would ordinarily be painful for him or her. It is critical that the patient be able to reliably elicit his or her pain with a particular position or activity. If this is not the case, the findings of the procedure will be difficult to interpret. The seated position is the most common provocative position used for the procedure. An injection of a small volume $(0.6 \mathrm{cc})$ of short-acting local anaesthetic (4\% lidocaine) or placebo control (normal saline) is then delivered into the disc, and the response of the patient to the anaesthetic or placebo is recorded (Figure 2). The authors chose a volume of $0.6 \mathrm{cc}$ for the injection as this volume is typically well below the volume of disc injection at which extravasation into the epidural space is noted on fluoroscopy during discography (1-1.5 cc in degenerated discs), and as such minimizes the likelihood of the anaesthetic effect being due to an epidural effect. 


\section{Figure 2.}

Functional Anaesthetic Discogram Data Sheet

\author{
Patient: \\ Proactive Discography Findings: \\ FAD Findings: \\ Level: \\ Pre-injection VAS: \\ Injection substance: \\ During injection VAS: \\ 5 minutes post: \\ 10 minutes post: \\ 20 minutes post:
}

\section{FAD data sheet.}

The initial injection of anaesthetic into the disc typically causes an exacerbation of the patient's typical low back pain, followed by, in positive cases, the onset of the effect of the $4 \%$ lidocaine in approximately $2-5$ minutes. The effect of the $4 \%$ lidocaine typically lasts 25-30 minutes, and then the injection can be repeated as necessary to confirm the diagnosis. We have designated a positive result as one in which the patient reports that the intradiscal delivery of the local anaesthetic causes a decrease in the visual analog scale (VAS) score of 2 points or greater during the provocative position or activity, and reports that the pain is significantly less than is typical for them. It should be that in this early experience with the technique, the choice of a VAS score decrease of 2 points as a threshold was somewhat arbitrary. This level was chosen because of the general consensus, reflected in the literature describing "successful" results of procedures done for patients with back pain, as well as the FDA assessment, ie, that this level of improvement at ultimate follow-up reflects a clinically significant improvement in pain. This level cannot be validated as an appropriate one until it can be correlated with successful clinical results after treatment.

Care must be taken to ensure that the insertion site is medial and inferior in Kambin's triangular zone of safety (formed by the traversing nerve root medially, the exiting nerve root laterally, and the inferior endplate inferiorly) to minimize the risk of irritation of the exiting nerve root during subsequent functional testing. At a higher lumbar disc of normal height, it may be possible to access the disc through an approach lateral to the exiting root, but the authors have no experience with the technique. If the exiting nerve root is irritated by the presence of the catheter, the interpretation of the test is more difficult. The usual strategy is to deliver local anaesthetic into the disc followed immediately by removal of the catheter. The patient is then instructed to compare his or her pain level during the provocative maneuver or position to his or her typical pain level. It should be remembered that the medial border of the exiting nerve root often abuts the lateral border of the inferior pedicle of the segment, and thus the appropriate spot on the posteroanterior (PA) radiograph for the outer needle to dock on the posterolateral margin of the annulus is in line with and proximal to the center of the inferior pedicle (Figure 3). In the setting of facet joint hypertrophy, docking on the annulus in line with the pedicle may require a bend to be applied to the outer needle to allow it to pass lateral to the facet joint.

\section{Figure 3.}

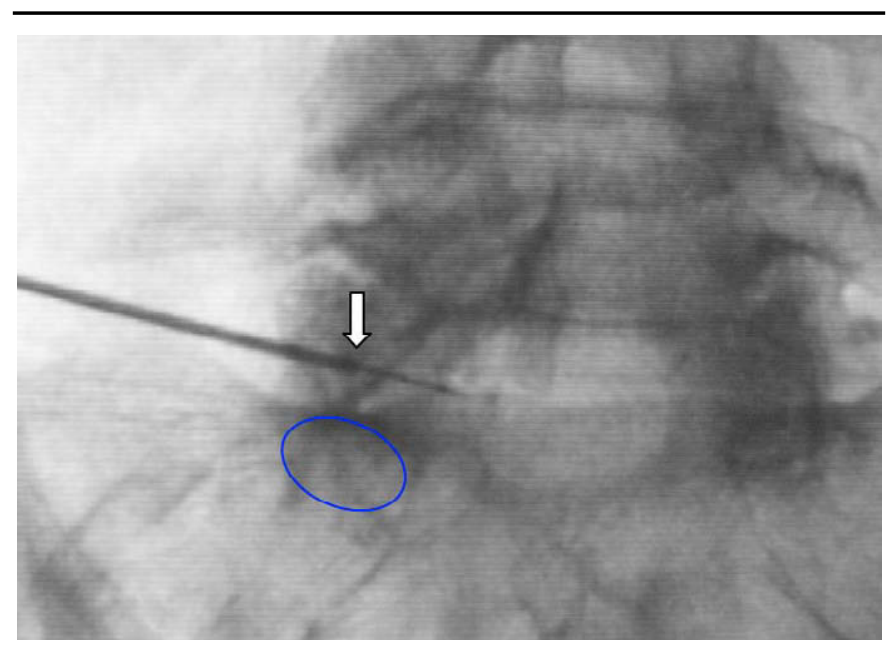

Appropriate docking site on posterior annulus (arrow) immediately superior to pedicle (oval).

\section{CASE PRESENTATION 1}

JK is a 29-year-old female nurse, otherwise healthy, who sustained an injury to her back at work while lifting a patient 2 years prior to her referral to the first author's practice. A workman's compensation claim was filed, and she was placed on disability as she was unable to continue working. An MRI scan at the time demonstrated disc desiccation and a small right-sided protrusion at the L5-S1 level; other levels were within normal limits.

She was treated over the subsequent several months with physical therapy, several epidural injections, antiinflammatories, and narcotic pain medication (acetaminophen/ oxycodone [Percocet], fentanyl [Duragesic] patch $25 \mathrm{mcg}$ ) with some benefit. Approximately 9 months later, her symptoms exacerbated, and a second MRI scan was obtained (Figure 4).

No significant interval changes were noted on comparison to the prior images. She then underwent provocative discography as her symptoms had not improved over this period of time after her injury. The exam was significant for severe concordant pain provocation at low pressure at the L5S1 level, without significant pain on injection at other levels. Based on the findings and her clinical presentation, she was treated at an outside institution with nucleoplasty (ArthroCare Corp., Sunnyvale, California) and an intradiscal injection of fibrinogen. Postoperatively she experienced improvement in her lower back pain symptoms for a period of 2 months, followed by recurrence of symptoms. After 8 months of recurrent severe pain, she was referred to the first author's practice for further evaluation and treatment. 
Figure 4.

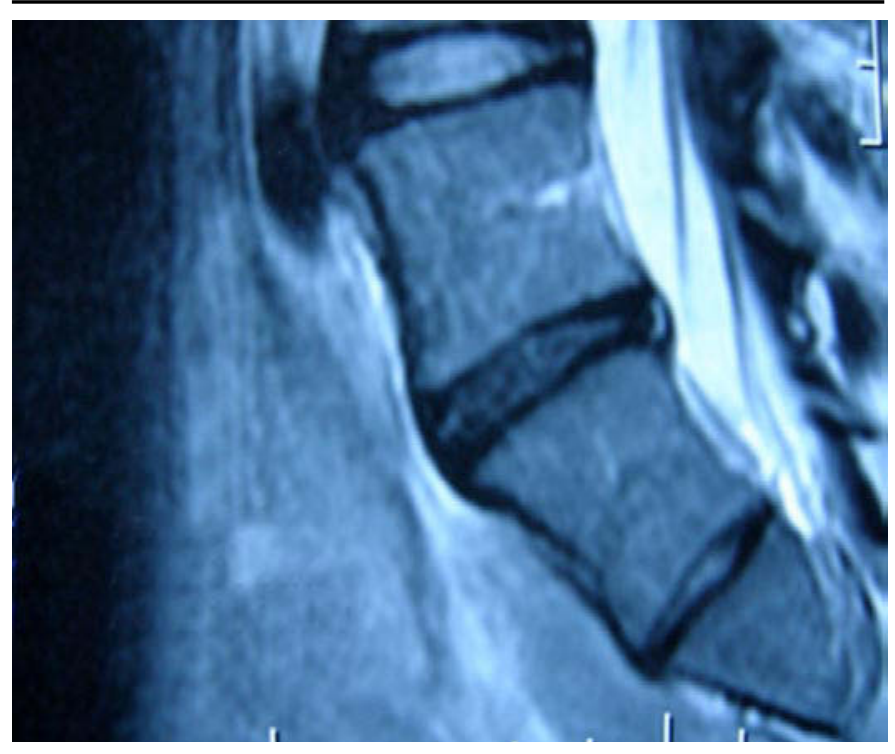

Preoperative MRI (Case 1).

Her chief complaint on evaluation was that of low back pain with intermittent radiation to her right buttock which was exacerbated by sitting as well as any vigorous activity. Her neurologic exam was within normal limits. She was at this point 10 months out from the nucleoplasty and fibrinogen injection, and back on narcotic medications (fentanyl patch $75 \mathrm{mcg}$, Percocet) as well as an anti-inflammatory (rofecoxib [Vioxx]). Her Oswestry score was 54\%, and her VAS for back pain was 7. Her score on the Zung Self-Rating Depression Scale was 28, and her modified somatic perceptions questionnaire (MSPQ) was 13. Because of the possibility that the previously positive provocative discogram could have been a false-positive test, a functional anaesthetic discogram was recommended and performed to obtain further diagnostic information.

The previous findings on provocative discography were confirmed, and a modified 20-gauge epidural catheter was inserted into the L5-S1 disc space. The patient was brought out of the operating room and allowed to recover from the sedation, and at this point was asked to sit to recreate her usual symptoms. In a double-blinded fashion, $0.6 \mathrm{cc}$ of normal saline and $4 \%$ lidocaine were alternately injected into the L5-S1 disc space at 30-minute intervals. No significant relief was obtained with normal saline; however, after the injection of 4\% lidocaine, her VAS score dropped from 9 to 2 within 5 minutes of the injection. Based on the results of the test, the patient subsequently underwent an L5-S1 posterior instrumented interbody fusion (Figure 5).

At her last visit, she was 2 years out from surgery. Her Oswestry score had improved from $54 \%$ to $2 \%$, and the VAS had improved from 8 to 1 . She was off all narcotics, and had returned to work as a case manager.

\section{Figure 5.}

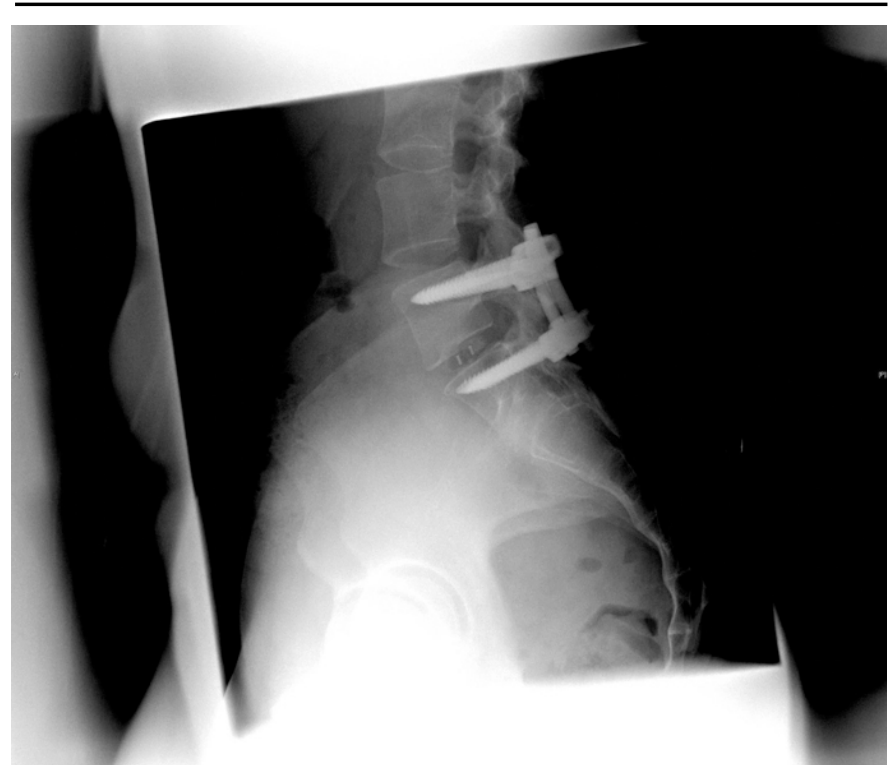

Postoperative lateral (Case 1).

\section{CASE PRESENTATION 2}

JS is a 36-year-old otherwise healthy female executive, who underwent a prior L5-S1 microdiscectomy at an outside institution for back and left lower leg pain 3 years prior to presentation. She did very well for about a year and a half with resolution of her left lower extremities symptoms. She subsequently developed progressive back and intermittent left lower extremity pain, and was referred on for evaluation to the senior author's practice. At that time she complained of lower back pain that she rated as 10/10, worst with sitting and activity. She also complained of left posterior calf pain, which predominantly bothered her during sleep. She was frustrated by her need to curtail her usual exercise activities, and was taking acetaminophen/hydrocodone (Vicodin) daily at a rate of 5-6 per day as well as Neurontin $900 \mathrm{mg} 3$ times a day. Her Oswestry score was $46 \%$, and her VAS for back pain was 9/10. Her MSPQ was 9, and her score on the Zung depression scale was 28 . Her back pain was much more significant than her left leg pain.

She had undergone 2 courses of physical therapy without significant benefit, and was treated with 2 epidural steroid injections with no sustained relief. MRI scanning was performed, and the findings were that of a small residual left-sided protrusion, with slight fibrosis in the region of the left S1 nerve root at the level of the disc space. Disc space desiccation and narrowing were noted at the L5-S1 level, with type 1 Modic changes present symmetrically in the L5 and S1 vertebral bodies adjacent to the disc space (Figure 6).

Disc desiccation, slight narrowing, and a high-intensity zone (HIZ) were noted at the L4-5 level. A provocative discogram was performed at an outside institution, with findings of 


\section{Figure 6.}

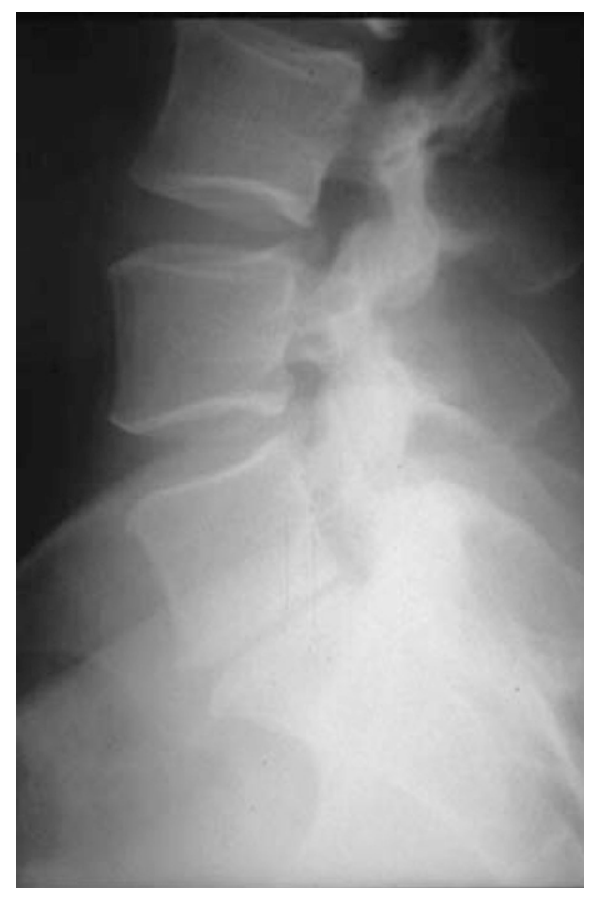

Preoperative lateral (Case 2).

concordant and severely painful L4-5 and L5-S1 injections at low pressure, with a painless injection of contrast at the L3-4 disc space. She was referred to our practice for surgical evaluation. A functional anaesthetic discography study was recommended and performed to obtain further diagnostic information.

The findings on provocation discography were replicated, and a modified $20 \mathrm{~g}$ epidural catheter was placed into each of the L4-5 and L5-S1 disc spaces. She was allowed to recover from the sedation, and then asked to assume a sitting position to elicit her usual symptoms. Double-blinded injections of $0.6 \mathrm{cc}$ normal saline and $4 \%$ lidocaine were sequentially performed into these two lumbar discs. No relief was noted with anesthetic in the L4-5 disc space, and her pain scale dropped from 8/10 to $2 / 10$ within 5 minutes after the injection of anaesthetic into the L5-S1 disc. Based on the results of the test, the patient underwent an L5-S1 anterior instrumented fusion (Figure 7).

At 1 year out from surgery, with radiographic signs of fusion, her Oswestry score had improved from $46 \%$ to $20 \%$, and her VAS score had improved from 9 to 3 . She stopped all narcotics 2 weeks after surgery and has been back to work on a full-time basis since 2 months after the surgery.

\section{CASE PRESENTATION 3}

DH is a 52-year-old male carpenter with a long history of chronic low back pain which began as a work-related injury 14 years prior to our evaluation. He was unable to work for approximately 4 months after that injury, but eventually

\section{Figure 7.}

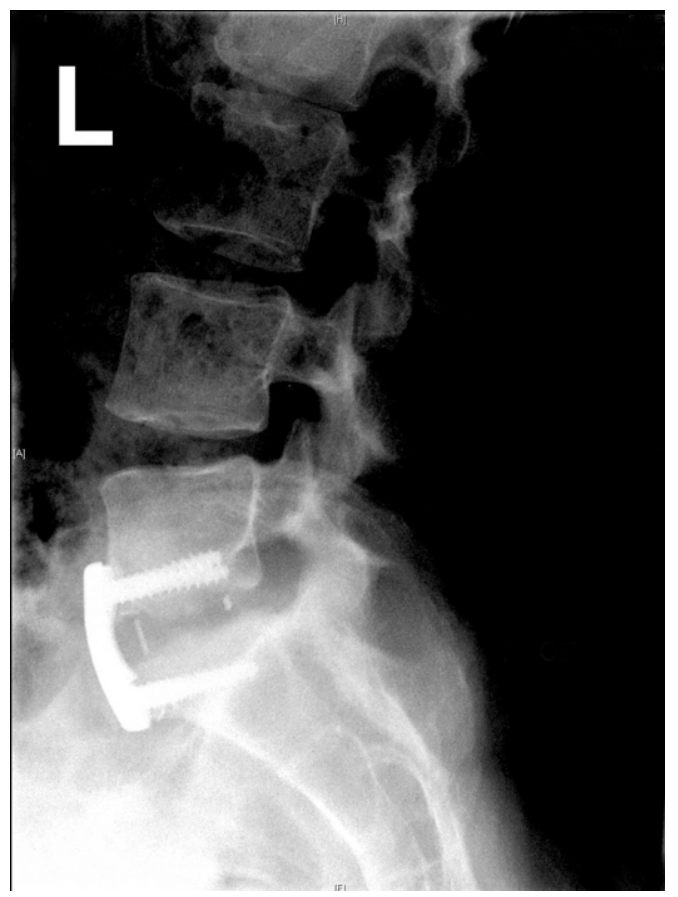

Postoperative lateral (Case 2).

returned to work and has had persistent chronic lower back pain since. Over the course of his treatment, he underwent multiple courses of physical therapy, epidural injections, and has chronically been on narcotic analgesics (Vicodin). He worked since the time of his injury as a carpenter until about 1 year prior to evaluation, but has had intermittent exacerbations of his back pain, which have in the past caused him to miss work for several weeks at a time. One year prior to evaluation, he again sustained an exacerbation of his back pain while at work and had been unable to return to work since.

An MRI scan that was obtained 7 months prior to evaluation demonstrated mild degenerative changes at L3-4, L4-5, and L5-S1 (Figure 8).

He was sent on to the first author's clinic for consultation regarding the advisability of surgical treatment of his condition. On initial evaluation, his chief complaint was of axial, non-radiating low back pain which he rated at $5 / 10$ on a visual analog scale. His Oswestry score was $44 \%$, his MSPQ was 2, and his Zung depression score was 32. A functional anesthetic discogram was recommended and performed to obtain further diagnostic information.

On provocative discography, a discordant pain response was noted on injection of the L3-4 disc space, while a concordant severe pain response was noted on injection of the L4-5 disc space at $<20$ pounds per square inch (psi) above the opening pressure. No significant pain was produced on injection of the L5-S1 disc space. Modified epidural catheters were placed into 
Figure 8.

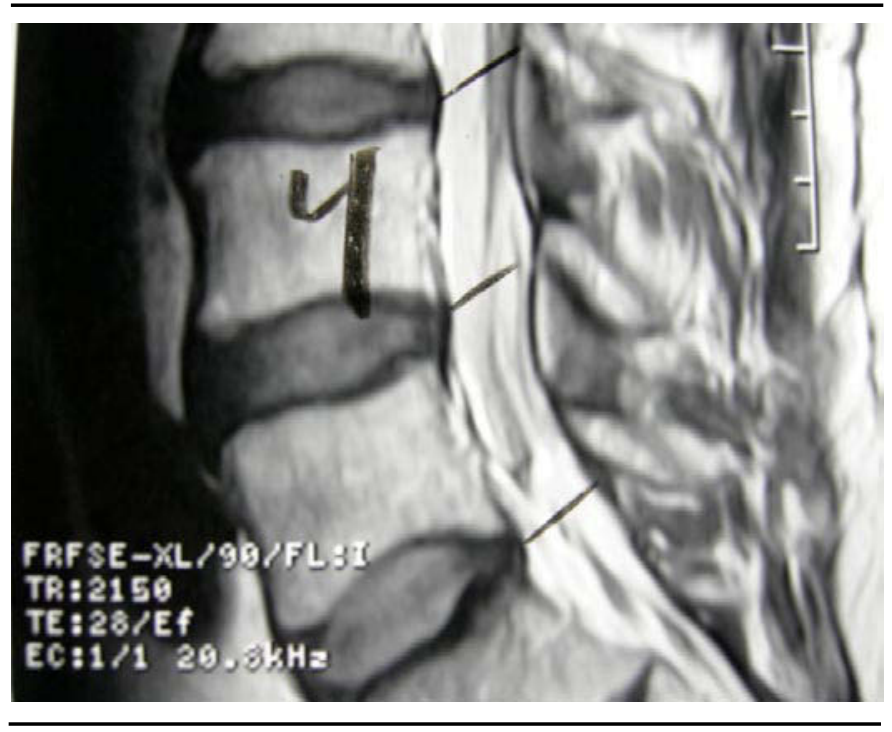

Preoperative MRI (Case 3 ).

the L4-5 disc space. After provocative positioning in the postanaesthesia care unit, a double-blinded series of injections was performed, and no relief was noted with anaesthetic in the L4-5 disc space. Fusion surgery was not recommended. After 1 more year of conservative management, his clinical condition is unchanged, with an Oswestry of $46 \%$ and a VAS score for pain of 6 .

\section{DISCUSSION}

We describe here a variant on provocative lumbar discography which we believe may prove to be a more specific method of diagnosis for discogenic low back pain than the other currently available techniques.

Anaesthetic discography is certainly not a novel concept; references can be found describing the utility of the technique. ${ }^{12-16}$ A diagnostic test that is anaesthetic has some theoretical advantages over an isolated provocative test: in the evaluation of a patient with chronic low back pain (who by definition is in a chronic pain state), it is intuitive that an anaesthetic response is likely to be more reliable than a provocative one. Anaesthetic injections in other parts of the body have been extensively used and are felt to be useful diagnostic techniques. ${ }^{17-20}$

Our new variant, the functional anaesthetic discogram, is designed to formalize anaesthetic discography in a way that more directly addresses the patient's clinical complaints. We hope the test will allow a more specific diagnosis to be made by allowing single lumbar levels to be individually tested. It further allows anaesthetic to be delivered to the lumbar disc while the patient is in a position that would ordinarily produce the back pain of which he or she complains. The quick on/ off contrast of the short-acting local anaesthetic (with the $4 \%$ lidocaine used in these cases, the decrease in pain typically occurs within the first 5 minutes of the injection) may increase the diagnostic gain of the test in assessing the source of the patient's primary complaint. The time to loss of anaesthetic effect of $4 \%$ lidocaine was noted to be approximately 25 minutes in these patients, allowing the test to be performed at multiple levels without the requirement of large amounts of time in the post-anaesthesia care unit.

These patients experienced no complications, and we believe it is unlikely that the placement of catheters into their discs during the procedure will cause disc degeneration. The longterm effect of the FAD catheter on the normal disc is not known but is unlikely to be different than the effect of a needle puncture of similar cross-sectional size into the disc. This effect is likely proportional to the cross-sectional diameter of the puncture, which in the initial attempt at this procedure was made with an 18-gauge needle, but with the current technique is now made with a 25 -gauge needle.

Several questions remain about this technique that will be answered with further study:

1) Test validity. How can we determine the validity of the functional anaesthetic discogram (or, for that matter, provocative discography) in the determination of the presence or absence of significant discogenic pain if a gold standard does not currently exist? In the absence of a widely accepted standard, investigators often use a proxy, but the most appropriate one in this disease process is not obvious. One reasonable proxy may be a successful 1-year outcome of fusion or arthroplasty in subjects with discogenic pain. Longer-term outcome may not be necessary to address the issue of test validity as longer-term outcome allows us to assess a different question, that is, the longer-term efficacy of treatment. Shorter-term follow-up seems more likely to directly answer the question of whether or not a correct diagnosis was made prior to surgery. This proxy method, while by no means perfect, would allow validation of the test applied in a systematic fashion in a prospective cohort study.

2) Test utility. Will the results of the test improve surgical outcomes more precisely than the current regimen of either imaging studies alone or provocative discography? We are examining this question in a preliminary clinical trial (20 surgical patients) comparing these outcomes to our historical data. The most definitive method would be to perform a provocative discogram and functional anaesthetic discogram in all subjects, and randomly assign the patients to a treatment regimen based on either the results of one study or the other. ${ }^{21}$ This sort of study design would clearly address the main issue of concern to patients and surgeons: Does the addition of the test in the diagnostic algorithm lead to improved clinical outcomes of fusion or arthroplasty? 
3) Mechanism of test action. What is the mechanism of the pain relief that we saw in the patients described here? It is clear from prior work that annular tears are innervated by nociceptive afferents from the ventral primary ramus and sinuvertebral nerve. ${ }^{22}$ Anaesthetic injected into the disc clearly penetrates these annular tears as they are noted radiographically with the injection of small volumes of contrast into the disc. Schmorl's nodes and the endplates are similarly innervated ${ }^{23}$ (in this case by the basivertebral nerve), and are likely to be infiltrated by local anaesthetic administered to the disc as they too are visible on discography.

\section{CONCLUSION}

As the complexity and expense of our treatment methods for presumed discogenic low back pain currently exceed our ability to diagnose and define the clinical disorder, there is an urgent need to devote more research resources to this critical part of the clinical management of chronic low back pain. We present these case studies and technical description as a first step in examining this method of preoperative assessment. Further study of the technique will allow us to make more definitive recommendations with regards to its validity and utility.

This manuscript was submitted November 9, 2007, and accepted for publication February 2, 2008.

\section{REFERENCES}

1. Fritzell P, Hagg O. 2001 Volvo Award Winner in Clinical Studies: Lumbar fusion versus nonsurgical treatment for chronic low back pain: a multicenter randomized controlled trial from the Swedish Lumbar Spine Study Group. Spine. 2001. 26(23):2521-32.

2. Mirza S. Point of View: Commentary on the research reports that led to Food and Drug Administration approval of an artificial disc. Spine. 2005. 30(14):1561-1564.

3. Blumenthal SL, McAfee PC, Guyer RD, et al. A prospective, randomized, multicenter Food and Drug Administration investigational device exemptions study of lumbar total disc replacement with the CHARITE artificial disc versus lumbar fusion: part 1: evaluation of clinical outcomes. Spine. 2005. 30(14):1565-1575.

4. Lindblom K. Technique and results of diagnostic disc puncture and injection (discography) in the lumbar region. Acta Orthop Scand. 1951. 20(4):315-326.

5. Derby R, Howard MW, Grant JM, et al. The ability of pressurecontrolled discography to predict surgical and nonsurgical outcomes. Spine. 1999. 24(4):364-371; discussion371-2.

6. O'Neill C, Kurgansky M. Subgroups of positive discs on discography. Spine. 2004. 29(19):2134-2139.

7. Guyer RD, Ohnmeiss DD. Lumbar discography. Position statement from the North American Spine Society Diagnostic and Therapeutic Committee. Spine. 1995. 20(18):2048-2059.

8. Guyer RD, Ohnmeiss DD; NASS. Lumbar discography. Spine J. 2003. 3(3 Suppl):11S-27S.

9. Carragee EJ,Tanner CM, Khurana S, et al. The rates of false-positive lumbar discography in select patients without low back symptoms. Spine. 2000. 25(11):1373-1380.
10. Vanharanta $\mathrm{H}$, Ohnmeiss DD, Aprill CN. Vibration pain provocation can improve the specificity of MRI in the diagnosis of symptomatic lumbar rupture. Clin J Pain. 1998.

11. Carragee EJ, Tanner CM, Yang B, Brito JL, Truong T. False-positive findings on lumbar discography. Reliablility of subjective concordance assessment. Spine. 1999. 24(23):2542-2547.

12. Kikuchi S, Macnab I, Moreau P. Localisation of the level of symptomatic cervical disc degeneration. J Bone Joint Surg BR. 1981. 63-B(2):272-277.

13. Kotilainen E, Muittari P, and Kirvela O. Intradiscal glycerol or bupivacaine in the treatment of low back pain. Acta Neurochir (Wien). 1997. 139(6):541-545.

14. Osler GE. Cervical analgesic discography. A test for diagnosis of the painful disc syndrome. S Afr Med J. 1987. 71(6):363.

15. Roth DA. Cervical analgesic discography. A new test for the definitive diagnosis of the painful-disk syndrome. JAMA. 1976. 235(16):17131714.

16. Finch PM, Khangure MS. Analgesic Disc and Magnetic Resonance Imaging. Pain. 1990. Supp 5:S285.

17. Hildebrandt J. Relevance of nerve blocks in treating and diagnosing low back pain--is the quality decisive? Schmerz. 2001. 14(6):474-483.

18. Tallia AF, Cardone DA. Diagnostic and therapeutic injection of the shoulder region. Am Fam Physician. 2003. 67(6):1271-1278.

19. Nikolaides AP, Dermon AR, Papavasiliou KA, Kirkos JM Coracoclavicular joint degeneration, an unusual cause of painful shoulder: a case report. Acta Orthop Belg. 2006. 72(1):90-92.

20. Blankenbaker DG, De Smet AA, Keene JS. Sonography of the iliopsoas tendon and injection of the iliopsoas bursa for diagnosis and management of the painful snapping hip. Skeletal Radiol. 2006. 35(8):565-571.

21. Sackett DL, Haynes RB. The architecture of diagnostic research. Br Med J. 2002. 324(7336):539-541.

22. Edgar MA, Ghadially JA. Innervation of the lumbar spine. Clin Orthop Relat Res. 1976. 115:35-41.

23. Brown MF, Hukkanen MV, McCarthy ID, et al. Sensory and sympathetic innervation of the vertebral endplate in patients with degenerative disc disease. J Bone Joint Surg Br. 1997. 79(1):147-153. 